\title{
Unilateral onycholysis in a patient taking erlotinib (Tarceva)
}

\author{
Robert Stevenson, Ahmed El-Modir \\ Oncology Department, University Hospitals Birmingham, Birmingham, UK \\ Correspondence to Dr Robert Stevenson, doctorrob@doctors.org.uk
}

\begin{abstract}
Summary
Targeting epidermal growth factor receptor (EGFR)-mediated signalling pathways has become routine practice in the treatment of lung cancer. Erlotinib is an oral EGFR tyrosine kinase inhibitor, licensed for maintenance monotherapy treatment in patients with locally advanced or metastatic non-small cell lung cancer after first-line chemotherapy. The authors present the case of a 51-year-old patient who had an excellent response to erlotinib, but developed unilateral onycholysis as an unusual side effect. The authors discuss erlotinib-induced skin and nail changes and have provided a brief literature review on the available evidence for their management.
\end{abstract}

\section{BACKGROUND}

The use of targeted agents such as epidermal growth factor receptor (EGFR) tyrosine kinase inhibitors (TKIs) is becoming more commonplace in the treatment of cancer. The side effects of most 'traditional' chemotherapeutic agents are well-characterised and most clinicians have a good grasp how to manage them effectively.

We have decided to write this particular case up, as first it highlights the substantial and sustained benefits that can be derived from targeted agents, and also because the patient involved developed an interesting and unusual side effect of erlotinib. The side effects of targeted drugs are very different from cytotoxics and we have attempted to briefly outline the nail changes and dermatological side effects associated with EGFR tyrosine kinase inhibitors and discuss their management.

\section{CASE PRESENTATION}

A 51-year-old gentleman was referred to the respiratory physicians with an abnormal chest x-ray after a 6 month history of chest symptoms. His chest x-ray demonstrated right lower and middle lobe consolidation, with bilateral patchy infiltrates, which had failed to respond to several courses of antibiotics (figure 1). A CT scan demonstrated widespread patchy consolidation, with lobar consolidation within the middle lobe. However, no central obstructing bronchial lesion or significant lymphadenopathy was demonstrated. A bronchoscopy did not show any abnormality and he was therefore referred for a video assisted thoracic surgical biopsy. Histology from right middle and lower lobe biopsies demonstrated a non-mucinous bronchoalveolar carcinoma.

He was referred for palliative chemotherapy and was commenced on docetaxel and carboplatin. Unfortunately, following the first cycle of chemotherapy, he was admitted with bilateral pneumothoraces and surgical emphysema affecting the chest and neck (figure 2). He responded to bilateral chest drains and a right-sided pleurodesis.

He received his second cycle of docetaxel and carboplatin chemotherapy, with some improvement in the appearance of the left lung, but no change in the right lung. However, he complained of severe fatigue, loss of appetite, weight loss and depression and opted to discontinue his chemotherapy treatment.

After 4 weeks of treatment, his chest x-ray showed evidence of progressive disease and was therefore started on second-line treatment with erlotinib $150 \mathrm{mg}$ once daily.

He tolerated his erlotinib treatment well, had grade 1 diarrhoea, and a grade 1 rash on his hands and feet, which responded to clindamycin and hydrocortisone cream. After only two cycles of erlotinib his chest x-ray demonstrated an excellent response with resolution of his bilateral lung shadowing (figure 3).

After five cycles of erlotinib the patient began to suffer with paronychia affecting the nails of his left hand and foot. In light of this, the dose of erlotinib was reduced to $100 \mathrm{mg}$ once daily. His paronychia settled with a course of antibiotics, however soon after he developed onycholysis, only affecting the nails on his left foot (figures $4 a, b$ ). Normal skin flora and Candida albicans were isolated from skin swabs taken from the patient.

The onycholysis has not required any treatment. The patient continues on erlotinib and has to date had 19 cycles with no evidence of disease progression.

\section{DISCUSSION}

We present the first recorded case of unilateral onycholysis in a patient taking erlotinib (Tarceva) for non-small cell lung cancer (NSCLC).

EGFR are often overexpressed or dysregulated in solid tumours, leading to uncontrolled cell growth, proliferation, angiogenesis and metastases. ${ }^{1}$ Targeting EGFR-mediated signalling pathways has become routine practice in the treatment of lung, pancreatic, renal cell, breast and gastrointestinal stromal tumours (GIST). ${ }^{1}$ Available EGFR TKIs include; erlotinib (NSCLC, pancreatic cancer), imatinib (GIST), sunitinib (renal cell carcinoma, GIST), pazopanib (renal cell carcinoma), gefitinib (NSCLC) and lapatanib (breast cancer).

Erlotinib is licensed for maintenance monotherapy treatment in patients with locally advanced or metastatic NSLC with stable disease after four cycles of standard platinum- 


\section{BMJ Case Reports}

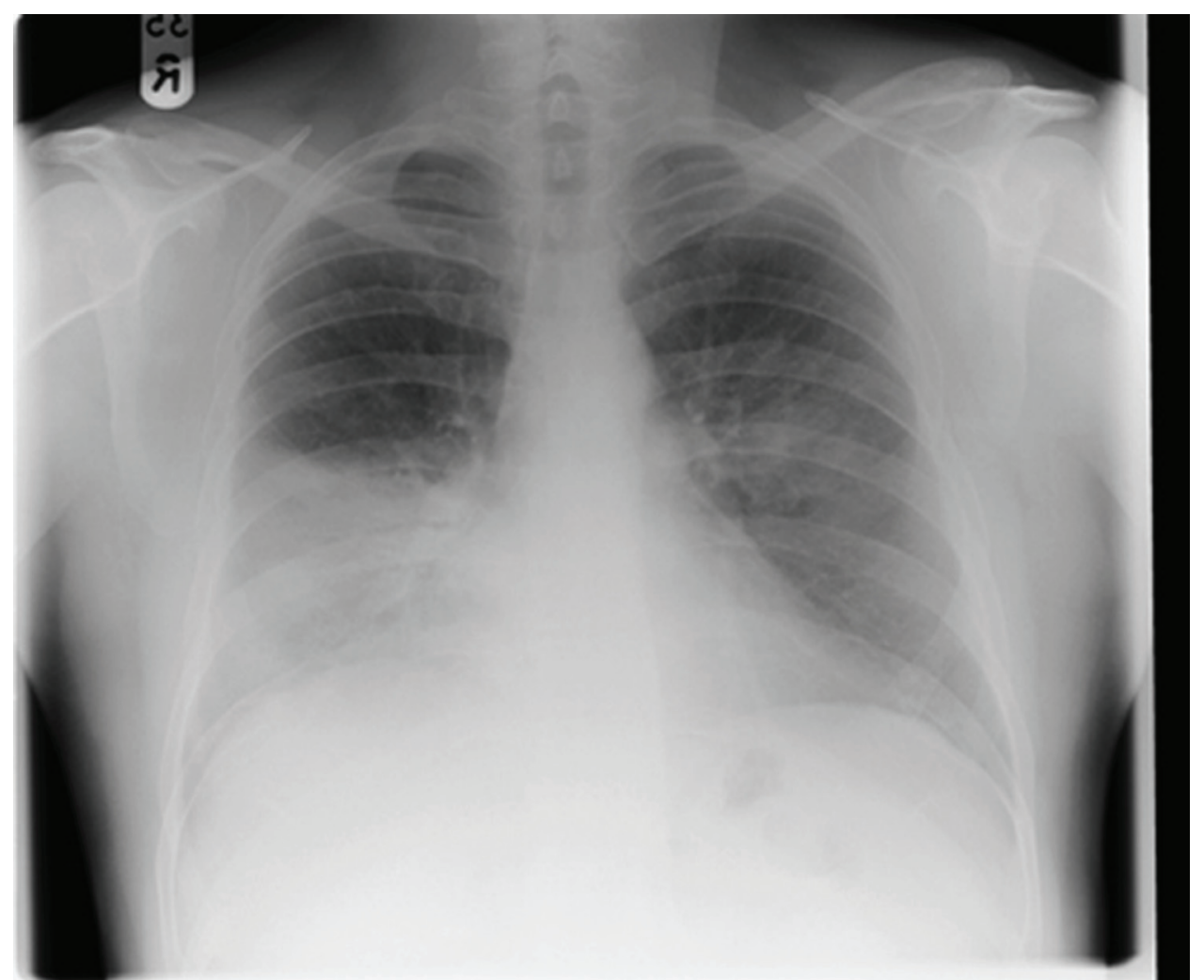

Figure 1 Presenting chest x-ray demonstrating lower and middle lobe consolidation, and bilateral patchy infiltrates.

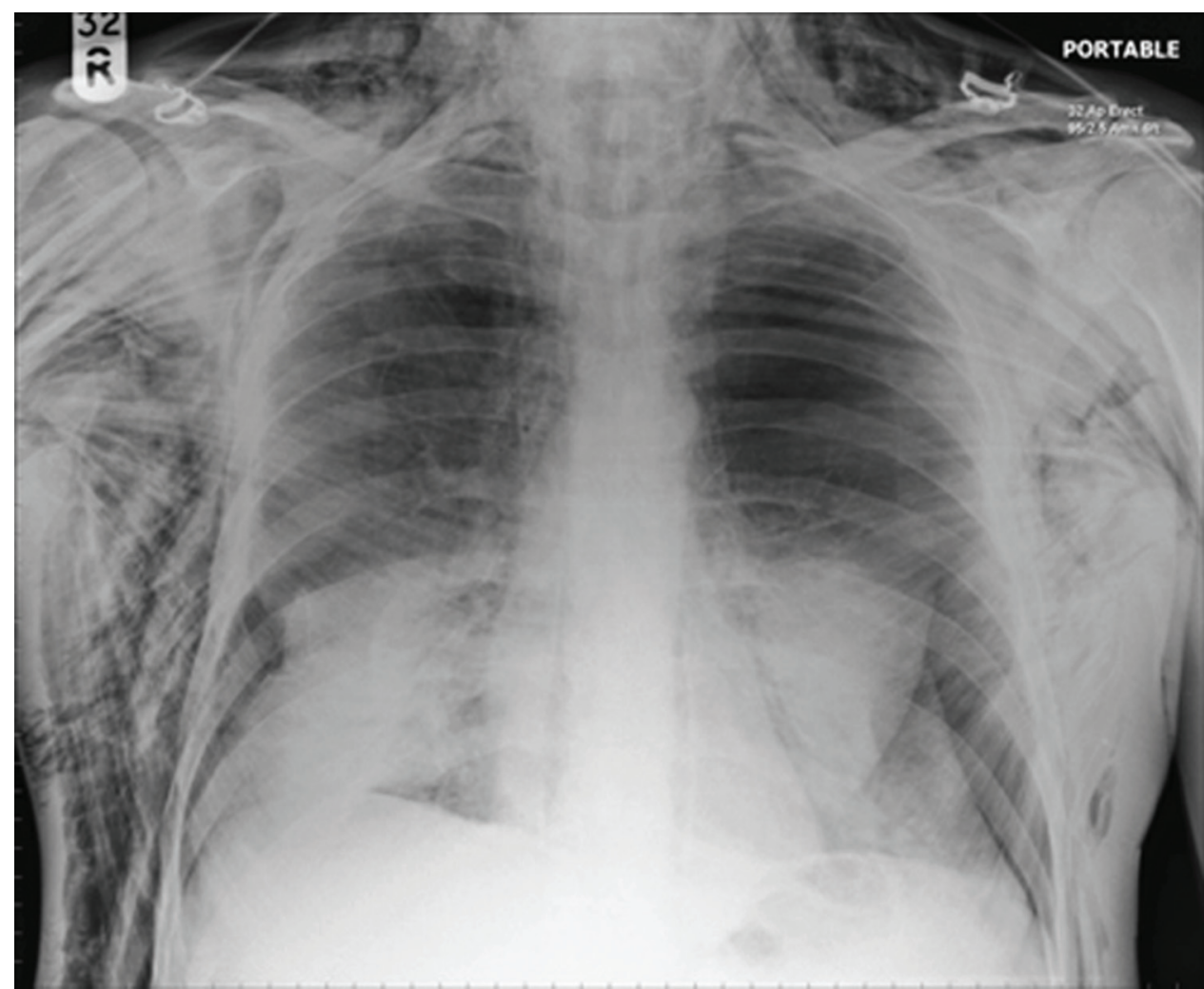

Figure 2 Chest x-ray demonstrating bilateral pneumothoraces with surgical emphysema affecting the neck and chest. 


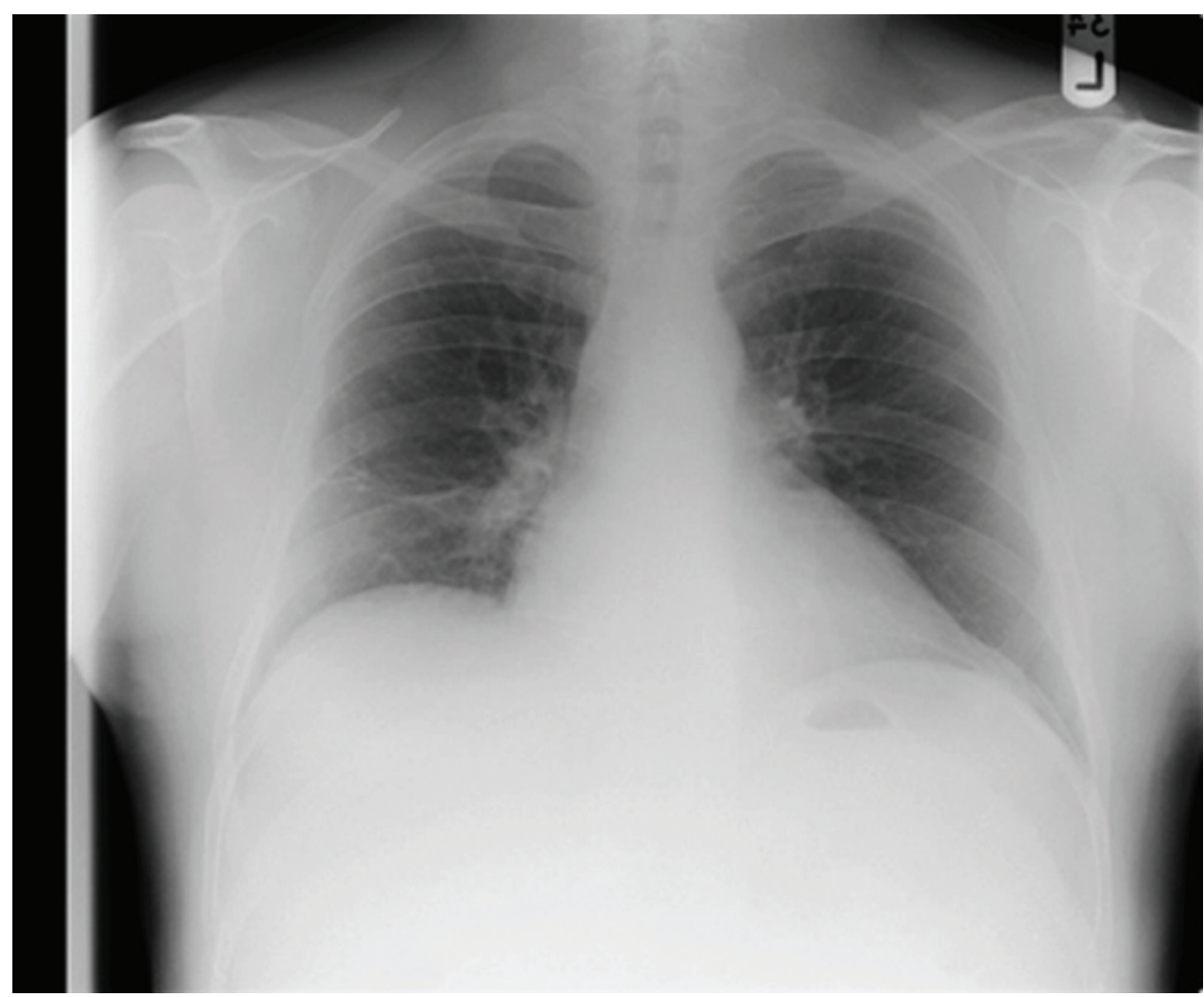

Figure 3 Chest x-ray after two cycles of erlotinib demonstrating resolution of the bilateral lung changes.

based first-line chemotherapy. It is also licensed for the treatment of patients with locally advanced or metastatic NSLC after failure of at least once prior chemotherapy regimen. ${ }^{2}$

In 2005, the National Cancer Institute of Canada Clinical Trials Group ${ }^{3}$ published the results of a phase III randomised trial (BR21 study) comparing erlotinib with placebo in stage III/IV NSCLC patients who had failed first- or second-line chemotherapy. They found the overall response rate to be $8.9 \%$ in the erlotinib arm compared with $1 \%$ in the placebo group $(p<0.001)$, and median overall survival to be longer in the erlotinib group (6.7 months, $95 \%$ CI 5.5 to 7.8 ) than in the placebo group (4.7 months, $95 \%$ CI 4.1 to 6.3). Based on the BR21 study, in November 2008, National Institute for Clinical Excellence recommended erlotinib as a clinically and cost-effective alternative to intravenous chemotherapy (i.e. docetaxel) for the second-line treatment of NSCLC. ${ }^{4}$ It however, rejected erlotinib for maintenance therapy in NSCLC after first-line chemotherapy.

Although EGFR TKI use has substantially reduced the haematopoietic and non-specific side effects of traditional chemotherapeutic agents, their use has many undesirable effects related to EGFR-mediated signalling pathway inhibition. The most common side effects of all EGFR TKIs are a papulopustular skin rash (45-100\% of patients) ${ }^{5}$ and diarrhoea $(50 \% \text { of patients })^{5}$; with the rash being dosedependent. ${ }^{7}$ Other effects on epidermal-derived tissue include dry skin, pruritus, ocular and nail changes (paronychia, onycholysis).

EGFR is expressed in the basal layer of the epidermis, and is thought to stimulate epidermal growth, inhibit differentiation and accelerate wound healing. ${ }^{1}$ Inhibition of EGFR-mediated signalling pathway results in impaired growth and migration of keratinocytes, increased cell attachment and differentiation, and increased inflammatory chemokine expression. ${ }^{16}$ These effects lead to inflammatory cell recruitment and subsequent cutaneous injury, which accounts for the majority of symptoms, including tenderness, papulopustules and periungual inflammation, and may also account for onycholysis. ${ }^{16}$

Onycholysis is listed as an uncommon (>1/1,000$<1 / 100)$ side effect of erlotinib treatment. ${ }^{5}$ Onycholysis is characterised by the spontaneous separation of the nail plate from its underlying and/or lateral supporting structures, starting at the distal free margin and progressing proximally. ${ }^{8}$ There are many causes of onycholysis including endogenous, exogenous, hereditary and idiopathic factors, of which contact irritants, trauma and moisture are the most common underlying cause. ${ }^{8}$

An important differential diagnosis for onycholysis is onychomycosis, a fungal infection that affects the finger and toe nails. Dermatophytes are thought to account for the majority $(90 \%)$ of cases of onychomycosis of the toenails and at least $50 \%$ of fingernail infections. ${ }^{9}$ Nondermatophytes such as Candida albicans, are also known to cause onychomycosis, ${ }^{9}$ however, despite frequent isolation of Candida spp. from the proximal nail fold or the subungal space of patients with chronic paronychia or onycholysis, Candida is only a secondary coloniser. ${ }^{9} 10$

Bilateral onycholysis is known to occur in patients receiving 5 -fluorouracil chemotherapy, ${ }^{8}$ and has previously been reported in patients taking erlotinib. ${ }^{11}$ On review of the available literature, only one case report of unilateral 


\section{BMJ Case Reports}
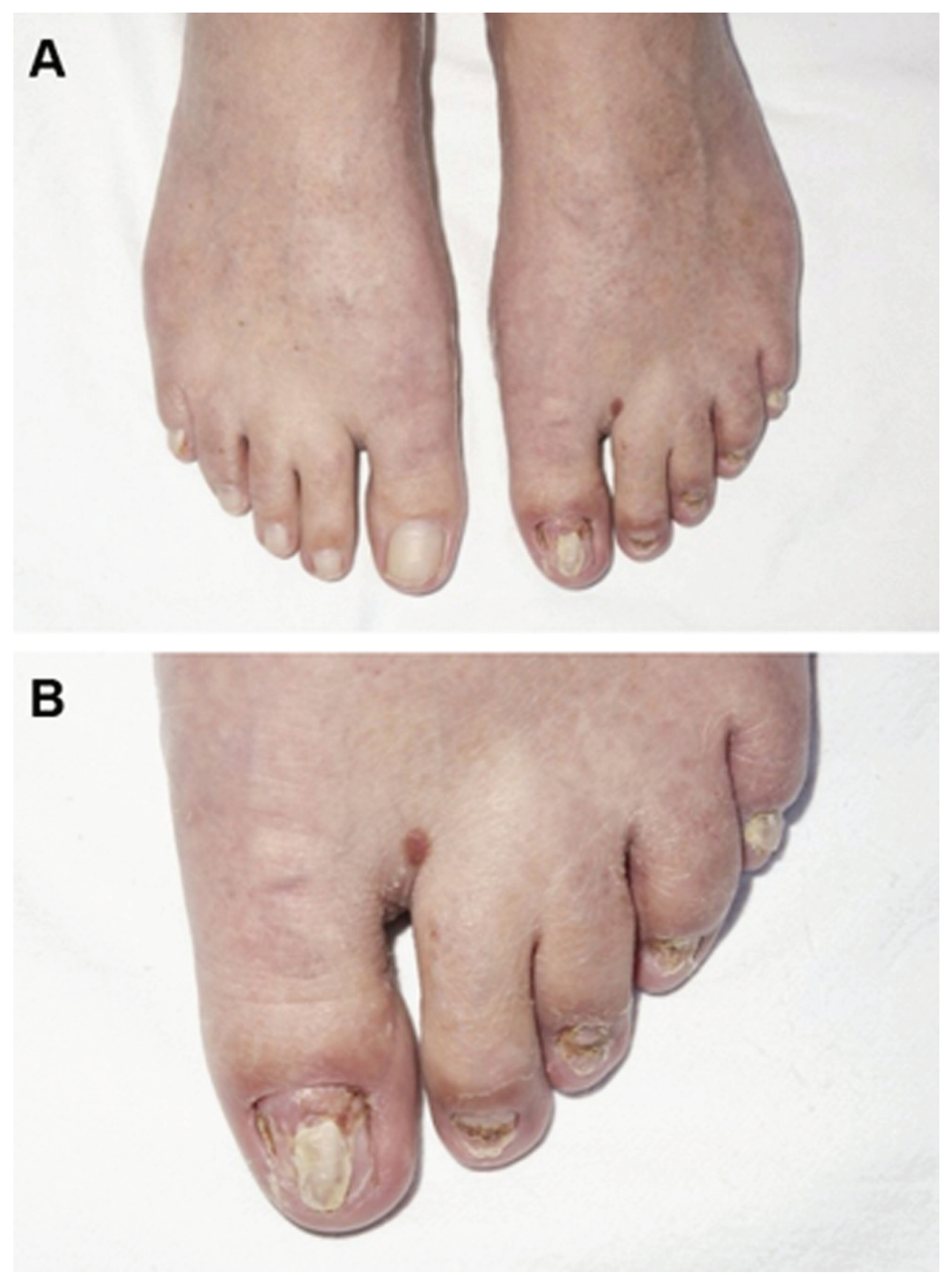

Figure $4(a, b)$ Unilateral onycholysis of the nails of the left foot (with permission from patient).

onychopathy was identified which was associated with chemotherapeutic agents. ${ }^{12}$ No cases however were found in patients treated with targeted agents.

It is unclear to why this patient would develop unilateral onycholysis, however as mentioned previously one of the most common causes of onycholysis is trauma. ${ }^{8}$ Prior to being treated with erlotinib, this patient had received two cycles of docetaxel and carboplatin chemotherapy, both of which are known to cause peripheral neuropathy. It is therefore, quite feasible that he may have acquired asymptomatic trauma secondary to chemotherapy-induced peripheral neuropathy, leading to the observed unilateral onycholysis.

Cutaneous side effects of EGFR TKIs are common and at their most severe can result in bullous, blistering and exfoliate skin conditions, including very rare cases of Stevens-Johnson syndrome/toxic epidermal necrolysis, which in some case have been fatal..$^{5}$ Management of such cutaneous manifestations can be challenging, especially with the use of topical agents, as patients who receive EGFR TKIs seem to be abnormally sensitive to irritants or allergens. ${ }^{6}$ Although treatment algorithms have been devised, ${ }^{13-15}$ there is currently no evidence-based treatment guideline to prevent or treat EGFR TKI associated skin or nail toxicities.

Potthoff et al. (2010) have recently published an extensive review on the management of EGFR-induced skin reactions. ${ }^{15}$ As paronychia is a more common side effect than onycholysis this review, like much of the available literature, ${ }^{7-16}$ concentrates on the management of paronychia. 
Non-pharmacologic interventions are aimed at prevention and protecting affected areas. Patients should be advised to wear loose-fitting shoes, soak their feet in a solution containing aluminium acetate or Epsom salts, and to avoid trauma to the cuticles, biting their nails, or cutting them too short as this may exacerbate the inflammation and potential for infection. ${ }^{16}$

If paronychia does occur it should be treated with daily antiseptic baths to avoid bacterial superinfection. Topical povidone-iodine-based ointments could be applied and hypergranulative tissue formations can be treated with silver nitrate application on a weekly basis. In severe cases, systemic oral antibiotics such as doxycycline or minocycline should be given, and when bacterial or fungal superinfection is suspected, systemic treatment should be altered based upon culture results and sensitivities. Interruption of EGFR TKI therapy should be considered only if treatment fails, and in such circumstances surgical nail removal may be helpful. ${ }^{15} 16$

Several clinical trials examining the role of different agents in preventing/treating EGFR TKI-induced skin rash are currently recruiting (NCT00473083, NCT00531934) ${ }^{17}$ or awaiting results reporting (NCT00910676, NCT00531934), ${ }^{17}$ however there are no recent clinical trials investigating the management of nail toxicities.

\section{CONCLUSION}

Although cases of bilateral onycholysis have been reported, this is the first recorded case of unilateral onycholysis in a patient taking the oral EGFR TKI erlotinib. While this case represents an interesting and unusual side effect of erlotinib, it also highlights the substantial benefits patients can derive from such targeted agents after failure on firstline chemotherapeutic agents, along with some of the side effects patients can experience example rash, diarrhoea, paronychia and onycholysis.

\section{Learning points}

- The EGFR tyrosine kinase inhibitor erlotinib is an effective second line treatment for advanced NSLC.

- Nail changes and dermatological side effects are a common side effect of all EGFR TKI.

- There are no evidence-based guidelines to prevent or treat EGFR TKI associated skin or nail toxicities.

- Onycholysis is an uncommon side effect of erlotinib treatment and is characterised by the spontaneous separation of the nail plate from its underlying and/or lateral supporting structures.

- EGFR TKI-induced paronychia is common, and its management involves topical antiseptic baths or ointments, systemic antibiotics and in severe cases surgery.
Competing interests None.

Patient consent Obtained.

\section{REFERENCES}

1. Lacouture ME, Melosky BL. Cutaneous reactions to anticancer agents targeting the epidermal growth factor receptor: A Dermatology-Oncology perspective. Skin Therapy Lett 2005;12 http://www.skintherapyletter. com/2007/12.6/1.html (accessed 15th January 2011)

2. Tarceva product information website. http://www.tarceva.net/portal/eipf/pb/ tarceva/erlotinib/home (accessed 15th January 2011)

3. Shepherd FA, Rodrigues Pereira J, Ciuleanu T, et al. Erlotinib in previously treated non-small-cell lung cancer. N Engl J Med 2005;353:123-32.

4. Erlotinib for the treatment of non-small cell lung cancer. NICE technology appraisal guidance 162. http://www.nice.org.uk/nicemedia/ live/11777/42657/42657.pdf (accessed 15th January 2011)

5. Tarceva approved EU product label. http://www.tarceva.net/fmfiles/re787003/ Product_Label/emea-combined-h618en.pdf (accessed 15th January 2011)

6. Lacouture ME. Mechanisms of cutaneous toxicities to EGFR inhibitors. Nat Rev Cancer 2006;6:803-12.

7. Segaert S, Van Cutsem E. Clinical signs, pathophysiology and management of skin toxicity during therapy with epidermal growth factor receptor inhibitors. Ann Oncol 2005; 16:1425-33.

8. Hecker MS, Hecker D. Onycholysis. http://emedicine.medscape.com/ article/1105738-overview (accessed 15th January 2011)

9. Elewski BE. Onychomycosis: pathogenesis, diagnosis, and management. Clin Microbiol Rev 1998;11:415-29.

10. Tosti A. Onychomycosis. http://emedicine.medscape.com/article/1105828overview\#a0104 (accessed June 28th 2011)

11. Samelis GF, Tsiakou A, Zaganides A, et al. Survival benefit with erlotinibbased chemotherapy in unoperable recurrent and/or metastatic pancreatic cancer. J Clin Oncol 2008;26:15622.

12. Truchuelo M, Vano-Galvan S, Pérez B, et al. Unilateral taxane-induced onychopathy in a patient with a brain metastasis. Dermatol Online $\mathrm{J}$ 2009;15:7.

13. Lynch TJ JrKim ES, Eaby B, et al. Epidermal growth factor receptor inhibitorassociated cutaneous toxicities: an evolving paradigm in clinical management. Oncologist 2007;12:610-21.

14. Lacouture ME, Basti S, Patel J, et al. The SERIES clinic: an interdisciplinary approach to the management of toxicities of EGFR inhibitors. J Support Oncol 2006;4:236-8.

15. Potthoff K, Hofheinz R, Hassel JC, et al. Interdisciplinary management of EGFR-inhibitor-induced skin reactions: a German expert opinion. Ann Oncol 2011;22:524-35.

16. Dunne M, Sumner D. EGFR inhibitors: Toxicities and Strategies for Effective management. http://www.medscape.org/viewarticle/579711 (accessed 5th february 2011)

17. Clinical trials registry. http://clinicaltrials.gov/ct2/results?term $=$ erlotinib + skin धpg =1 (accessed 5th february 2011) 


\section{BMJ Case Reports}

This pdf has been created automatically from the final edited text and images.

Copyright 2011 BMJ Publishing Group. All rights reserved. For permission to reuse any of this content visit http://group.bmj.com/group/rights-licensing/permissions.

BMJ Case Report Fellows may re-use this article for personal use and teaching without any further permission.

Please cite this article as follows (you will need to access the article online to obtain the date of publication).

Stevenson R, El-Modir A. Unilateral onycholysis in a patient taking erlotinib (Tarceva). BMJ Case Reports 2011;10.1136/bcr.04.2011.4157, date of publication

Become a Fellow of BMJ Case Reports today and you can:

- Submit as many cases as you like

- Enjoy fast sympathetic peer review and rapid publication of accepted articles

- Access all the published articles

- Re-use any of the published material for personal use and teaching without further permission

For information on Institutional Fellowships contact consortiasales@bmjgroup.com

Visit casereports.bmj.com for more articles like this and to become a Fellow 